\title{
Commentary: Do not fear the ascending aorta
}

\author{
Matthew R. Byler, MD, MBA, ${ }^{\mathrm{a}}$ and Irving L. Kron, $\mathrm{MD}^{\mathrm{b}}$
}

\author{
From the ${ }^{\mathrm{a}}$ Division of Thoracic and Cardiovascular Surgery, University of Virginia, Charlottesville, Va; and \\ ${ }^{\mathrm{b}}$ Department of Surgery, University of Arizona Health Sciences, Tucson, Ariz. \\ Disclosures: Authors have nothing to disclose with regard to commercial support. \\ Received for publication May 24, 2019; accepted for publication May 24, 2019; available ahead of print July 11 , \\ 2019. \\ Address for reprints: Irving L. Kron, MD, Department of Surgery, College of Medicine-Tucson, University of \\ Arizona Health Sciences, 1501 N Campbell Ave, PO Box 245017, Tucson, AZ 85724 (E-mail: kron@email. \\ arizona.edu). \\ J Thorac Cardiovasc Surg 2020;159:1681-2 \\ $0022-5223 / \$ 36.00$ \\ Copyright (C) 2019 by The American Association for Thoracic Surgery \\ https://doi.org/10.1016/j.jtcvs.2019.05.055
}

Dilation of the ascending aorta has been commonly associated with cardiac pathology, including connective tissue diseases, aortic stenosis and insufficiency, and bicuspid aortic valve. Furthermore, patients with dilated ascending aortas after undergoing cardiac operations may be at risk for progressive aortic dilation (necessitating a difficult reoperative replacement), for aortic dissection, or for rupture. Current guidelines recommend replacing the ascending aorta for those with dilation measuring greater than 4.5 to $5.5 \mathrm{~cm}$, depending on patient risk factors. Some surgeons are taking a more aggressive approach toward proximal aortic replacement when patients are undergoing concomitant cardiac surgery. This can prevent the patient from needing to undergo a second reoperative procedure and prevent further worsening of aortic disease or comorbidities.

In this issue of The Journal of Thoracic Cardiovascular Surgery, Idrees and colleagues ${ }^{1}$ examine the outcomes of ascending aortic replacement in patients undergoing concomitant cardiac surgery at their high-volume cardiac surgery center. ${ }^{1}$ Their study evaluated 647 patients in a 5 -year period who underwent an elective primary cardiac operation with concomitant aortic replacement. These patients were propensity matched with a group undergoing cardiac surgery without aortic intervention, and no added risk was found for in-hospital stroke $(0.93 \%$ vs $0.46 \%)$ or mortality ( $1.4 \%$ vs $1.1 \%)$. Although it would be difficult to do so retrospectively, it would be interesting to perform this analysis with a standardized method for cerebral perfusion, because Idrees and colleagues ${ }^{1}$ included both anterograde and retrograde cerebral perfusion in patients who underwent circulatory arrest.

In addition to their analysis on a large number of patients for whom cardiac disease was the primary indication for surgery, Idrees and colleagues ${ }^{1}$ also evaluated the outcomes of patients for whom aortic disease was the primary indication for surgery. These patients tended to have more advanced disease, which has been demonstrated to carry an increased risk of morbidity and mortality. Consistent with these previous studies, Idrees and colleagues ${ }^{1}$ found

\section{References}

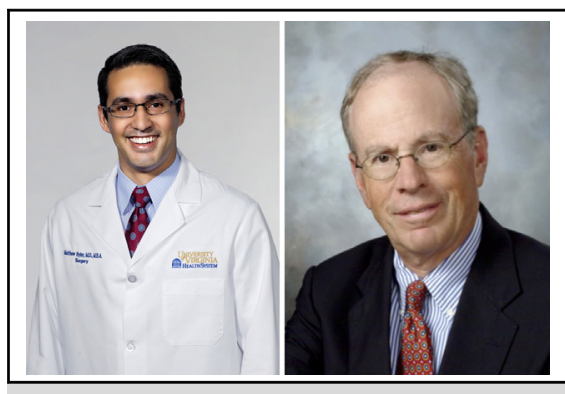

Matthew R. Byler, MD, MBA (left), and Irving L. Kron, MD (right)

Central Message

Replacement of a dilated ascending aorta during concomitant elective cardiac operations can be performed safely without increasing risk to the patient.

See Article page 1669.

this population of patients to have a high rate of in-hospital stroke $(6.5 \%)$ and a high mortality $(7 \%){ }^{2}$ Despite advancements in operative technique and in myocardial and cerebral protection, replacement of the ascending aorta with advanced disease continues to carry an increased risk of morbidity and mortality.

The novelty of this study is that Idrees and colleagues ${ }^{1}$ considered several cardiac operations in concert with ascending aortic replacement, although a large majority of their cases $(77 \%)$ involved aortic valve replacement. Similarly, in 2007 we evaluated 146 patients who underwent aortic valve replacement with proximal aortic replacement and also found there to be no increased morbidity or mortality as compared to a similar cohort undergoing aortic valve replacement alone. ${ }^{3}$ Whereas we considered those patients in whom proximal aorta measured $5 \mathrm{~cm}$ or greater, Idrees and colleagues ${ }^{1}$ were slightly more aggressive in considering those with an aorta of more modest size (mean of $4.8 \mathrm{~cm}$ ).

The excellent results from this well-performed study adds to the growing body of literature demonstrating that concomitant aortic replacement and cardiac operations can safely be performed in the elective cardiac surgical population. Surgeons should evaluate their institutional capabilities for the management of these complex cases and consider referral to aortic centers to ensure reproducibility of these results.

1. Idrees JJ, Roselli EE, Blackstone EH, Lowry AM, Soltesz EG, Johnston DR, et al Risk of adding prophylactic aorta replacement to a cardiac operation. J Thorac Cardiovasc Surg. 2020;159:1669-78.e10. 
2. King RC, Kanithanon RC, Shockey KS, Spotnitz WD, Tribble CG, Kron IL. Replacing the atherosclerotic ascending aorta is a high-risk procedure. Ann Thorac Surg. 1998;66:396-401.
3. Reece TB, Singh RR, Stiles BM, Peeler BB, Kern JA, Tribble CG, et al. Replacement of the proximal aorta adds no further risk to aortic valve procedures. Ann Thorac Surg. 2007;84:473-8; discussion 478. 